\title{
Significação dos alunos e pedagogos da EJA: a importância da escola como fator protetivo e promotor de resiliência
}

\section{Meaning of eja students and pedagogues: the importance of school as a protective factor and promoter of resilience}

Jamille Mansur Lopes ${ }^{1 *}$, Francismara Neves de Oliveira ${ }^{2}$, Luciana Ramos Rodrigues de Carvalho $^{3}$, Maria Fernanda Maceira Mauricio², Sidnei Lopes Sanchez Júnior ${ }^{4}$

\begin{abstract}
RESUMO
Apoiada na teoria Bioecológica do Desenvolvimento Humano (BRONFENBRENNER, 1996), buscou-se a significação do ambiente escolar de acordo com as vivências dos alunos e pedagogos da Educação de Jovens e Adultos (EJA), considerando fatores de risco e proteção presentes nesse contexto. A pesquisa qualitativa e descritiva analisou as significações produzidas por 12 alunos e 4 pedagogos da EJA. Pode-se concluir que a Educação de Jovens e Adultos permite a retomada de um direito que foi negado por diversas razões. A escola deve atuar no sentido de diminuir as desigualdades que assolam os menos favorecidos, além de ser responsável por constituir redes de apoio e promover a construção de fatores protetivos aos estudantes e demais membros dessa ecologia de desenvolvimento: familiares, amigos, corpo profissional da escola, comunidade adjacente. Assim, é notável considerar a EJA em sua função protetiva e promotora de resiliência, visto que desenvolve em seus alunos possibilidade de enfrentamento aos riscos, fortalecendo a dignidade humana e formando cidadãos de direitos.
\end{abstract}

Palavras-chave: Educação de Jovens e Adultos. Resiliência; Modelo Bioecológico de Desenvolvimento; Escola; Fator protetivo;

\begin{abstract}
Supported by the Bioecological Theory of Human Development (BRONFENBRENNER, 1996), we sought the meaning of the school environment according to the experiences of students and pedagogues of Youth and Adult Education, considering risk and protection factors present in this context. The qualitative and descriptive research analyzed the meanings produced by 12 students and 4 pedagogues of the institution participated. It can be concluded that Youth and Adult Education allows the resumption of a right that was denied for several reasons. The school must act to reduce the inequalities that plague the poor, in addition to being responsible for building support networks and promoting the construction of protective factors for students and other members of this development ecology: family, friends, school staff, adjacent community. Thus, it is noteworthy to consider Youth and Adult Education in its protective function and promoter of resilience, as it develops in its students the possibility of coping with risks, strengthening human dignity and forming citizens with rights.
\end{abstract}

\footnotetext{
${ }^{1}$ Universidade Pitágoras Unopar *E-mail: jamille_mansur@hotmail.com

${ }^{2}$ Universidade Estadual de Londrina

${ }^{3}$ Centro Universitário Filadélfia

${ }^{4}$ Universidade Federal do Paraná
} 
Keywords: Youth and Adult Education; Resilience; Bioecological Development Model; School; Protective factor;

\section{INTRODUÇÃO}

A Constituição Federal (BRASIL, 2016) em seu artigo 205 afirma a educação como direito de todo cidadão e dever civil e político do Estado, no sentido de sua universalização. Contudo, Haddad (1997) destaca a incapacidade de o Estado garantir a escolarização básica na idade adequada, o que fica evidente no artigo 208 da Constituição que garante a oferta do ensino básico para aqueles que não tiveram acesso na idade apropriada. A Educação de Jovens e Adultos (EJA) se tornou modalidade de ensino da Educação Básica por meio da aprovação da Lei de Diretrizes e Bases da Educação Nacional (LDBEN) (BRASIL, 2017) que discorre sobre a oferta da EJA para àqueles que não tiveram acesso ou continuidade de estudos no ensino fundamental e médio. Desta forma, os sistemas de ensino devem assegurar e oportunizar o acesso aos estudos, considerando as características do alunado, interesses, condições de vida e de trabalho.

Diante do desafio de resgatar um compromisso histórico da sociedade brasileira, a EJA se configura como modalidade da educação que visa oportunizar igualdade e oportunidades de inclusão e justiça social. Assim, a LDBEN preconiza a idade mínima para os cursos de EJA e para a realização de exames de conclusão de EJA no Ensino fundamental, quinze anos completos, enquanto a idade mínima para matrícula em cursos de EJA de Ensino Médio e a realização de exames de conclusão de EJA do Ensino Médio é de dezoito anos completos (BRASIL, 2017).

Por meio do Parecer $n^{\circ}$ 11/2000, o Ministério da Educação homologou as Diretrizes Curriculares Nacionais da Educação de Jovens e Adultos, afirmando que a EJA busca reparar uma dívida social aos que não tiveram acesso à escola na idade própria e nem domínio da escrita e leitura como bens sociais. São elencadas três funções na organização desta modalidade: reparação, equalização e qualificação processo educativo (BRASIL, 2000). Entretanto, políticas públicas para EJA, paliativas e escassas na legislação, retratam o território esquecido e invisibilizado em diferentes instâncias no decorrer da história. A busca da EJA por um espaço na Educação Básica atravessa os tempos e atualmente visa superar as perspectivas de erradicação do analfabetismo, além 
de questões estruturais de exclusão política, socioeconômica e cultural que produzem o não acesso à escola e a evasão escolar (DI PIERRO, 2010).

Hadadd (1997) discorrera na mesma linha destacando que a regulamentação do acesso e da oferta de vagas para o Ensino Básico Universal não é suficiente para sua democratização, uma vez que, além dessas medidas, é necessário fomentar condições que assegurem a frequência regular, a permanência e o pertencimento à escola, a fim de não acarretar a culpa pelo fracasso escolar ao próprio sujeito que está excluído do ensino de qualidade. O processo histórico de escravidão, migração, dizimação de indígenas, trabalhadores braçais e outras minorias, são aspectos históricos e sociais que devem ser considerados, uma vez que foram negligenciados no decorrer da história. Arroyo (2005, p.221) chama a atenção para o fato de que a EJA "[...] é uma modalidade do trato dado pelas elites aos adultos populares", tendo em vista que todo percurso histórico é marcado pelo domínio de classes sociais mais favorecidas, das condições socioeconômicas desfavorecidas e estruturas de poder, que transcendem a esfera educacional.

Arroyo (2005) destaca que os que frequentam a EJA têm como realidade social a opressão, exclusão e pobreza. A condição de ser pobre advém não só de uma situação financeira e social, mas sim de um histórico de pobreza e exclusão, de origem e nascimento. É uma condição social e não simplesmente uma exclusão por si só. Essas realidades não devem ser negligenciadas por meio de uma nomenclatura escolar, como por exemplo: "repetentes, defasados, aceleráveis, analfabetos, candidatos à suplência, discriminados, empregáveis" (ARROYO, 2005, p. 223). Ao denominá-los dessa forma, se deixa de lado a dimensão da condição humana, evidenciando a culpabilização do fracasso ao aluno. O fato é que se deve ter uma visão global do alunado da EJA, como ser de direitos que busca concretização como um ser "pleno, social, cultural, cognitivo, ético, estético, de memória" (ARROYO, 2005, p. 226).

As ações pedagógicas na EJA, como em todas as modalidades da educação, não podem negar-se a promover que estudantes se percebam sujeitos, identifiquem as contradições existentes na sociedade e busquem transformar a realidade social, política, econômica e cultural na qual vivem e atuam (BARRETO, 2006). Dessa forma, a emancipação e a afirmação da identidade cultural são vistas como objetivos pelos quais a Educação de Jovens e Adultos deve se orientar, agregando a isso, elementos e valores que contribuam para que o processo aconteça de forma crítica. Com base nesses dados de realidade social, política e educacional e pouco debate no meio acadêmico (LOPES; 
OLIVEIRA; CARVALHO; GODOI, 2020). Discutimos a seguir uma temática de relevância ao contexto e à prática pedagógica: a produção da resiliência no ambiente escolar em especial, na EJA.

As marcas sociais produzidas nos contextos de desenvolvimento exercem grande força no processo de humanização e construção da cidadania, estabelecendo diversas interações do indivíduo com o ambiente e com os outros humanos com os quais se integra nesse contexto. Tomou-se por aporte teórico, o Modelo Ecológico de Desenvolvimento, pela valorização dada neste campo teórico aos contextos de desenvolvimento, os processos que neles têm lugar e as possibilidades de construção de sentido, positivo ou negativo, decorrentes. Não há, neste modo de conceber o desenvolvimento humano, um fator determinante, e sim uma ecologia de desenvolvimento que oportuniza muitas formas de interação: "aquilo que importa para o comportamento e o desenvolvimento é o ambiente conforme ele é percebido, e não conforme ele poderia existir na realidade 'objetiva"” (BRONFENBRENNER, 1996, p. 6). Dessa forma, a intervenção deve acontecer com o propósito de produzir desenvolvimento, romper a estagnação. Por isso, compreender as relações entre fatores de risco e de proteção (resiliência) nos processos de desenvolvimento humano é importante para a Teoria Bioecológica (BRONFENBRENNER, 2011).

O sujeito ou pessoa em desenvolvimento é visto, por meio de suas interações, como um ser em constantes mudanças em um ambiente "complexo, integrado e mutável" (BRONFENBRENNER, 2011, p. 27). As interações são, portanto, extremamente amplas por envolverem ambientes externos ao que o indivíduo vivencia diretamente. Nelas, a pessoa produz significados para as situações vividas. A significação decorre das vivências e, é por meio da significação que existe a possibilidade de intervenção e conhecimento das situações de risco e proteção que foram vivenciadas nos sistemas do modelo Bioecológico (BRONFENBRENNER, 1996).

Assim, as significações podem resultar em resiliência e produzirem modificação nas interações e nos sentidos atribuídos às vivências. No contexto do Modelo Bioecológico, o processo de resiliência é compreendido como condição de enfrentamento ao risco, no qual o sujeito sai modificado, transformado, nunca ileso (CYRULNIK, 2001; POLETTO; KOLLER, 2008; DELL'AGLIO; KOLLER; YUNES, 2011).

A resiliência está intimamente vinculada ao desenvolvimento e crescimento humano, mas para que haja um desenvolvimento saudável, é necessário que as relações 
interpessoais sejam equilibradas e vinculadas ao afeto. A resiliência acontece por intermédio de uma estrutura dialética que não envolve a eliminação da condição aversiva, mas a mudança do significado atribuído. Desse modo, resiliência é o equilíbrio entre risco e proteção e se relaciona às oportunidades vivenciadas e significações que o sujeito faz de sua própria história.

O risco, por sua vez, pode ser desmistificado como fator que gera resultados negativos e pode servir de base (ressignificação de sentidos) para a construção de atitudes de enfrentamento positivo, dependendo intrinsecamente da forma como é percebido pelo indivíduo (POLETTO; KOLLER, 2008).

A resiliência é um processo que pertence a um ambiente, a uma cultura, relacionase a uma história. O sofrimento, por vezes é irremediável, mas novas possibilidades a partir de um determinado acontecimento podem ser pensadas e alteradas (MELILLO; OJEDA, 2005; CYRULNIK, 2001). É na adoção dessa concepção de resiliência que passamos a ponderar sobre a escola como contexto no qual ela pode ser promovida e em especial, a EJA como espaço de ressignificação dos riscos, do não acesso e da invisibilidade.

A redes de interações e relações entre os principais ambientes na vida permite compreender o humano em constante movimento (nas dimensões sociais, culturais e no processo de significação) com variáveis interligadas e inter-relacionadas, com base no tempo, na pessoa, no processo e contexto. Estas interações não acontecem de forma singular e isolada, mas de maneira constante e mútua. Tanto o ambiente exerce uma influência no indivíduo, como o indivíduo exerce uma influência no ambiente. Libório e Koller (2009) corroboram essa ideia analisando o impacto da ausência contínua da criança na escola afetando o desenvolvimento para além da cognição interferindo negativamente na evolução socioemocional. Para os autores, a função social da escola ultrapassa as aprendizagens formais e atinge a saúde emocional.

De acordo com Dell'aglio e Koller (2011), há qualidade diferenciada nas relações interpessoais que se estabelecem no ambiente escolar. $\mathrm{O}$ aluno dedica boa parte do seu tempo a esse microssistema, também, as relações dos alunos entre pares e com profissionais da escola podem promover fontes de apoio social, emocional e de informações diferentes daquelas desenvolvidas em outros contextos de desenvolvimento como família, vizinhança. A escola pode ser classificada como um ambiente diverso, com variedades de conhecimento e relações, muitas vezes conflituosas, com problemas ou 
diferenças. Além disso, o microssistema escolar tem função social ao reelaborar conhecimentos produzidos socialmente, garantindo acesso formal, por parte de uma instituição formal (DESSEN; POLONIA, 2007).

O espaço social faz parte da construção da identidade do sujeito, em especial na adolescência. Dessa forma, é importante que o aluno, como ser ativo, se sinta pertencente a esse sistema e queira frequentar esse espaço de trocas sociais. Em especial isto é importante para o estudante da EJA que já vivenciou a exclusão da escola, advinda de relações sociais e políticas igualmente excludentes. A noção de pertencimento no ambiente escolar é percebida e trabalhada por meio das interações que desenvolvem identificação social e devem acontecer ao longo da vida do indivíduo, especialmente na escola, favorecendo a diminuição da evasão escolar (AMPARO; ALCES; CÁRDENAS, 2004).

A EJA é, por sua natureza, um contexto em que os riscos atuaram fortemente na vida dos estudantes, produzindo marcas tão intensas que os levou à significação de não pertencimento à escola. De acordo com Bruniera et al., (2018, p. 138): “A ausência do pertencimento pode resultar em expectativas divergentes entre alunos, professores e gestores, constituindo-se em uma escola alheia à realidade do aluno e configurada como espaço de exclusão e fracasso".

Defende-se a ideia, portanto, de que a escola não é em si mesma risco ou proteção. Pode em suas interações, na ecologia que constitui, favorecer processos excludentes em seu interior, produzir risco ao desenvolvimento dos envolvidos e dificultar o pertencimento promovendo a evasão, ou pode promover saúde e resiliência, desenvolver autoestima, autoeficácia e relações de apego, ou pode, "preparar os alunos no enfrentamento das adversidades, auxiliando-os na superação de uma situação de risco de formas mais saudáveis” (DELL'AGLIO; KOLLER, 2011, p. 118).

Assim, as pessoas inseridas nesse contexto, como professores e alunos, se tornam recursos emocionais, o que fortalece o desenvolvimento, por meio da interação recíproca. Sendo assim, a escola pode ser caracterizada como um recurso na formação humana, cidadã de direitos e responsabilidades, partilhadas pela socialização, promovendo apoio social e afetivo mútuos. 


\section{MÉTODO}

A pesquisa foi de abordagem qualitativa e caráter descritivo. Adotou-se nesse estudo, o uso de entrevista, mas que se guiou pela necessidade de oportunizar condições de livre relato, apenas desencadeado por alguma provocação advinda de uma pergunta quando o assunto não era espontaneamente trazido no relato oral, tornando esse momento um processo interativo, com influência mútua entre pesquisador e entrevistado, e, para que assim fosse, valorizou-se a criação de um bom vínculo entre pesquisadora e participante. A pesquisa foi aprovada pelo Comitê de Ética em Pesquisa Envolvendo Seres Humanos (CEP-UEL) (Parecer número: 3.142.014) e todo material e informações adquiridos na pesquisa foram assegurados em sigilo a fim de garantir a preservação da identidade dos sujeitos pesquisados e, posteriormente, serem eliminados.

Participaram do estudo 12 alunos do Ensino Médio matriculados na EJA, sendo 3 mulheres e 9 homens com idades que variavam de 20 a 49 anos, identificados como A1, A2, A3, A4, A5, A6, A7, A8, A9, A10, A11 e A12 e 4 pedagogos atuantes na mesma escola e diretamente relacionados à EJA, denominados (P1, P2, P3 e P4).

A entrevista foi individual tanto com o estudante quanto com o pedagogo e versava sobre o sentido atribuído à EJA (no caso do estudante) e sobre a percepção do pedagogo acerca de percebem a relação dos estudantes com a EJA. A análise dos dados buscou reconhecer fatores de risco e de proteção presentes nos relatos orais de estudantes e seus pedagogos.

\section{FATORES PROTETIVOS QUE EMERGIRAM NOS SENTIDOS ATRIBUÍDOS PELOS ESTUDANTES À ESCOLA, AO ESPAÇO QUE FREQUENTAM - EJA}

Predominou nos relatos dos estudantes o sentido positivo atribuído ao ambiente escolar por ter proporcionado a eles, mudança de contexto, de perspectiva de vida, satisfação pessoal, aumento de conhecimento e interação pessoal, promovendo o desenvolvimento e o desejo de permanência nesse microssistema, a EJA.

Mesmo que o aluno busque primordialmente a escola como fonte de qualificação, pode se deparar com outras possibilidades para além desta: a função das vivências escolares. Os processos proximais desse microssistema podem contribuir no desenvolvimento humano, minimizando fatores de risco e promovendo fatores protetivos. Por isso, a escola deve se configurar como um microssistema de proteção, promotora de 
resiliência: "espaço de aprendizagem, de trocas afetivas, de socialização, de construção de autonomia e de ação protagônica" (DELL'AGLIO; KOLLER, 2011, p. 133).

Tal protagonismo se manifesta na descoberta de um saber antes ignorado:

(A6, MASCULINO, 23 ANOS): Ah, está sendo legal, né? Uma pessoa que não tinha base nenhuma voltar a estudar agora, conhecer coisa nova. Na escola tinha assunto que eu nem sabia, em biologia, tinha assunto que eu não sabia, nem o que era $\mathrm{H}^{2} \mathrm{O}$, de nada. Literalmente eu era uma pessoa ignorante. Agora está sendo legal aprender coisas novas.

(A11, MASCULINO, 48 ANOS): Ah, pra mim está sendo bom. Eu gostei. Porque, como se diz, está servindo para bastante coisa, a gente está aprendendo. [...] Aqui você tem a explicação, você tem a informação, você aprende. É um jeito melhor de aprender.

(A6, MASCULINO, 23 ANOS): Ah, está sendo bacana, porque a EJA, meio que eu comecei do Ensino Fundamental, eu não tinha nem base. Ela me deu a base. [...] Aí eu comecei a aprender coisa nova, a matemática, eu não sabia nem regra de 3, aí eu aprendi. Aí foi só evoluindo.

No reconhecimento de uma construção pessoal e novas perspectivas de vida:

(A6, MASCULINO, 23 ANOS): Se for descrever aqui na EJA, eu diria que é um avanço pessoal incrível que eu estou tendo, seria uma visão de futuro, para onde eu posso ir? Vários caminhos. Voltando a estudar aqui, vai abrir vários caminhos para mim. Agora eu posso escolher o que eu quero fazer, onde eu posso trabalhar, eu posso escolher um emprego agora! [...] Agora eu posso ter um filho e falar "eu posso te ensinar matéria”, eu vou lá e ensino.

No prazer, na satisfação, no reconhecimento de si como eficaz:

(A8, FEMININO, 49 ANOS): Ó, na minha vida...olha, conteúdo me traz felicidade, me traz alegria, esperança. Eu tenho planos para o futuro, sabe? Eu não tenho tanto medo mais, antes eu era muito depressiva, muito chorona, medrosa. Tudo é muito importante, tudo é muito bom. Eu não sei, eu acho que me trouxe satisfação. Eu gosto de ler, hoje eu consigo pegar um livro de 300 páginas e ler. Hoje eu consigo ler um livro de 500 páginas, eu consigo terminar um livro em 3 meses, coisa que eu não fazia. Me trouxe conhecimento, me trouxe alegria. É muito gostoso. Tudo isso diante dos estudos.

Na percepção de que é cidadão de direitos:

(A8, FEMININO, 49 ANOS): Eu não sei muito, mas eu sei dos meus direitos, sei também dos meus deveres, sabe? Em tudo. Eu sou melhor com meus filhos, eu sou melhor comigo mesma, eu sou melhor com as pessoas ao meu redor, sabe? E eu acredito no conhecimento, e eu fico olhando na minha filha e babando nela, ela fica olhando em mim e babando em mim, sabe? Porque foi tudo com muita dificuldade, ela faz faculdade, é um curso pago, eu sou empregada doméstica, eu sou diarista, eu não tenho..., Mas graças a Deus eu consigo, eu sei avaliar a importância disso. Eu não quero que ela seja doméstica. Não que não seja digno, pedreiro, servente, se você varre, não importa, se você está trabalhando o dinheiro é seu, é digno. Mas eu sei que a gente tem capacidade de conseguir coisas melhores, eu tenho, ela tem, você tem, 
todo mundo tem, só que exige bastante. Tem dia que você não está aguentando, tem problemas e você enfrenta coisas por todos os lados.

(A10, MASCULINO, 26 ANOS): Ah, tô gostando, comecei a ler mais, interagir com outras pessoas, porque antes era de casa, tipo, ia na academia, ficava ali nesse mundo. Aí é questão de aprendendo também, o professor fala bastante das as coisas acontecem, tipo lá fora, no mundo. Que nem agora, essa reforma da previdência, eles estão fazendo essa palestra aqui, ontem eu vim, daí você já aprende mais coisas também. É mais a questão do aprender para mim que tá sendo bom.

Nas possibilidades de interação, de relacionamento, de pertencimento:

(A8, FEMININO, 49 ANOS): Aqui, assim, é muito legal. Você vai encontrar (na EJA) pessoas jovens, pessoas de meia idade, pessoas um pouquinho mais vivida, um pouquinho mais experientes, tem de tudo e todo mundo trata todo mundo muito bem. Desde a direção, os professores, os meninos da secretaria. É sem palavras, sem igual. Ainda hoje eu estava conversando com a menina e eu falei: "eu vou sentir muita saudade, muita falta desse lugar". Todo mundo te trata como ser humano, não importa isso, aquilo, ou aquilo outro, é ser humano, todo mundo aqui respeita cada um, do seu jeito, como é, todo mundo se respeita e isso faz você ter vontade de ficar aqui. Você quer estudar, você quer estar no meio dessas pessoas, você é acolhido, todo mundo é acolhido, todo mundo... é muito bom. É uma benção de Deus, é uma benção de Deus.

(A9, FEMININO, 45 ANOS): Ah, pra mim tem sido bom, sabe? Aí você foge da rotina, senão é casa, igreja, trabalho, aí você não tem contato com as pessoas, você não conversa com as pessoas assim.

O relato positivo das vivências escolares na EJA, evidencia a escola como um fator protetivo para estes alunos. A inserção de um novo microssistema promove novas interações e processos proximais, promovendo desenvolvimento e formação da identidade pessoal (BRONFENBRENNER; MORRIS, 2006).

Os alunos reconhecem que a EJA proporciona mais do que o conhecimento formal, ela os auxilia na formação como um todo, sendo um sistema ecológico protetivo, rotineiro e de contato direto, o que aumenta ainda mais sua influência na vida dos alunos. O ambiente escolar promove proteção aos alunos, melhorando sua autoestima, tomada de decisão, comunicação, visão de mundo, entre outros. Tais aspectos podem se tornar uma variável compensatória à exposição de risco, pois aumentam o repertório do aluno, possibilitam desenvolvimento e adaptação (CABRAL; CYRULNIK, 2015).

Entende-se que a forma como os alunos significaram o retorno aos estudos como algo valorativo, indica processos de resiliência constituídos, permitindo enfrentamento aos riscos que os levaram ao abandono da escola e ressignificação que permitiu a eles, nova vinculação com o contexto escolar. 


\section{A PERCEPÇÃO DOS PEDAGOGOS SOBRE AS VINCULAÇÕES ESTABELECIDAS ENTRE OS ESTUDANTES E O CONTEXTO ESCOLAR DA EJA}

$\mathrm{Na}$ entrevista com os pedagogos, foi possível observar correspondência com as significações dos estudantes no que concerne à compreensão do contexto da EJA como fator protetivo. Os pedagogos significaram os estudantes como vítimas de exclusão social, destacando a importância da EJA como uma forma de resgate à dignidade, mudança de vida e autoestima reatando um elo rompido no processo de desenvolvimento, quando o direito de estudar foi perdido. Apresentamos o excerto da fala dos pedagogos quando convidados a falar de sua percepção do que a EJA significa aos estudantes, destacando 3 aspectos que emergiram de suas falas:

1. EJA como aspectos emocionais, resgate da própria história e da dignidade e promoção da autoestima:

P3: eles (alunos da EJA) tentam resgatar essa autoestima. Que a maior parte tem uma baixa autoestima, e eles (professores) trabalham muito esse lado deles, eles se tornam, vamos dizer assim, um pouco mais próximo deles... Trabalhos, projetos, né tudo que envolvam um pouco mais eles, do que no Regular (ensino) o professor não consegue. Eles (alunos da EJA) querendo ou não, já foram excluídos, já são excluídos. Muitos até pelo sistema.

P1: [ ] autoestima, eles sentem que precisam participar, a gente percebe, às vezes, pessoas idosas já, os filhos já se formaram, aí eles continuam estudando, porque é um sonho que tinham e não conseguiu realizar.

P2: Tem muitos alunos que vêm buscar o próprio resgate, [...] muitos voltam para buscar o resgate da própria cultura, da própria história, se dá o direito de voltar a estudar novamente. [...] o que chama mais atenção para a gente é essa força de vontade que eles têm, independente de várias dificuldades que eles passam, né? De estar tentando voltar para resgatar essa história que eles queriam que tivesse tido sucesso anteriormente e não conseguiu ser. Acho que é o principal, o que chama atenção. [...] Porque a gente observa a exclusão deles da escola, eles sentem muito. Não é "não quero estudar e não quero", é a questão social dos colegas, então, eles sentem bastante isso.

2. A função social da EJA, a condição dessa modalidade de ensino ser agente na promoção de mudanças e melhoria na qualidade de vida do aluno.

P3: O primeiro (mudança) que eu acho mesmo é o social. É ser acolhido, então, fazer parte realmente. [...] Eu acho que esse retorno, o fato deles fazerem parte de um grupo, ser bem aceitos. A gente percebe que tem uns aqui que não conseguem entrar em grupo nenhum, às vezes esse aluno é mais fácil dele parar (os estudos). [...] para os jovens, essa questão social é muito importante. Então, queira ou não, aqui a gente 
consegue conversar, tirar eles da rua, orienta. Lógico que eles fazem ali fora a gente não vai..., mas... assim, o que a gente pode orientar, esse contato que tem com os mais velhos, poder dizer que a gente pede respeito, né? A gente fala bastante no respeito para eles. Então a gente não tem problema dos mais novos com os mais velhos. Então, eu acho que para eles, em certo ponto, é bom esse contato. A gente não vai mudar muita coisa por enquanto, mas quem sabe no futuro...

3. O papel do professor que atua na EJA:

P4: Eu acho que na EJA os alunos têm uma formação como um todo. O professor da EJA ele pensa diferente, ele age diferente, então ele ensina o aluno não só a questão de português, de matemática, mas a questão da vida, né? E também vai de encontro com aquilo que o aluno traz também. Os nossos alunos, eles são de várias idades, já têm várias vivências e eles aproveitam muito isso que o aluno traz. Então o aluno sai daqui com uma bagagem muito grande. Das disciplinas, do conteúdo, mas também de relacionamento, de convivência. Que é muito importante também. [...] eu acho que toda educação promove mudança, tanto aqui como no regular. É uma coisa que eles pararam eles vão continuar a ter uma questão de uma melhora, um emprego no futuro, então eu acho que é sempre essa questão da melhora. Os trabalhadores querendo crescer no trabalho, os alunos de inclusão eles têm o sonho que é terminar... Muitos falam em fazer faculdade.

A fala dos pedagogos apresentou consonância tanto com a dos alunos, como com a reflexão feita pelos autores com os quais dialogamos neste artigo. A condição social do aluno da EJA envolve pobreza, opressão e exclusão (ARROYO, 2005). Estes alunos são esquecidos socialmente e carregam consigo preconceito por não concluírem seus estudos no tempo apropriado (HADDAD, 1997; BRASIL, 2000; DI PIERRO, 2010).

Por isso, cabe refletir que essas condições favorecem um contexto de vulnerabilidade tal, que necessita de atenção e intervenção institucionais. Nesse sentido, o papel da escola apresenta-se fundamental, tanto no processo de construção de nova identidade pessoal e social, quanto na construção de estratégias de enfrentamento aos riscos. Isto implica reconhecer, portanto, que a escola se constitui um microssistema matricial no desenvolvimento da pessoa, o que favorece processos de resiliência (DELL'AGLIO; KOLLER; YUNES, 2011).

Nessa perspectiva, a escola tem como objetivo a socialização dos alunos e "pode promover a autoestima e autoeficácia dos estudantes, capacitando-os em habilidades sociais, além de intensificar o relacionamento entre o grupo de iguais" (KOLLER; MORAIS; PALUDO, 2016, p. 155). Portanto, o microssistema escolar, em especial a EJA, é um ambiente facilitador de desenvolvimento e de renovação de oportunidades sociais e de aprendizagem, em que o aluno é um ser ativo. 
O apoio social é interativo entre pessoa e ambiente e evolui ao longo da vida e pode ser construído em todos os ambientes e sistemas dos quais o estudante em desenvolvimento se integra. (HABIGZANG; DINIZ; KOLLER, 2014). Nesse sentido, dividir características, vivências e experiências com outros desenvolve a ideia de pertencer a algum grupo ou contexto. Por isso, o microssistema escolar se torna um ambiente promissor na medida em que promove relações significativas e corrobora o processo de resiliência do aluno. Sendo um contexto de apoio, a escola priorizará a permanência do aluno e estudará continuamente meios de promover seu desenvolvimento (BRUNIERA et al., 2018).

No caso do estudante da EJA, é particularmente importante reconhecer que afastados por longo tempo da escola, tendem a restringir seu campo de interações à família e amigos. A inserção no ambiente escolar amplia as condições de desenvolvimento, posto que aumenta suas interações entre pessoas, objetos e símbolos: "quanto maiores as possibilidades de relações estabelecidas e a inserção em diferentes microssistemas, maiores as oportunidades de obtenção de recursos que favorecem o desenvolvimento humano" (KOLLER; MORAIS; PALUDO, 2016, p. 249).

A garantia do direito à educação, pela legislação vigente (LDB, ECA, Constituição Brasileira), compromete o poder público, por intermédio da educação, a minimizar a pobreza e as desigualdades sociais e garantir o espaço de relação com o saber sistematizado, aos estudantes da EJA. De acordo com Santos (2019, p. 11) "escola como espaço que acolhe, resguarda, não expõe, cuida, educa e, por isso, protege". Assim, a intervenção do Estado busca envolver o indivíduo que não frequenta o ambiente escolar e inseri-lo em um novo contexto que tende a ser protetivo (HABIGZANG; DINIZ; KOLLER, 2014).

Considerando tais fatores, a escola intercede na transmissão não só de conhecimentos formais, mas na aquisição de reconhecimento de direitos. O conhecimento adquirido nesse sistema perpassa outros, aos quais o estudante tem acesso, mesmo que indiretamente. Uma pessoa que se desenvolve na escola interage com os outros sistemas e expande seus conhecimentos, modificando e sendo modificada. Dessa forma, a escola tende a promover uma rede de apoio social aos alunos, por intermédio dos processos proximais, com relações significativas, tornando-se um ambiente protetivo e promotor de resiliência (MELILLO; OJEDA, 2005). 
A interação direta e contínua que ocorre nos microssistemas contribui para que os processos proximais aconteçam, promovendo o desenvolvimento (BRONFENBRENNER; MORRIS, 2006). Dessa forma, a escola é um microssistema que deve promover, além da educação formal, a construção de redes de apoio e socialização, buscando contribuir na formação integral do indivíduo, como propõe a LDB (BRASIL, 2017). Cabral e Cyrulnik (2015, p. 160) reiteram tal afirmação ao dizer que "pode-se chegar a uma cultura escolar preparada não apenas para 'transmitir conteúdos', mas para proteger ativamente seus estudantes e familiares". A escola deve ser um ambiente promotor de resiliência na medida em que potencializa interações significativas, especialmente por meio do professor.

Assim, a escola contribuiu na promoção do desenvolvimento humano e no processo de resiliência desses alunos ao auxiliar no rompimento de um ciclo vicioso caracterizado por um ambiente vulnerável e oportunizar diferentes interações com seus pares, com o conhecimento e favorecendo novas significações à vida, ampliando repertórios comportamentais.

\section{DISCUSSÃO}

A EJA constitui-se contexto escolar que permite a retomada de um direito que foi negado anteriormente por diversas razões. É inegável que a escola deve atuar no sentido de diminuir as desigualdades que assolam os menos favorecidos, os alunos que foram inseridos no mercado de trabalho precocemente, necessitando abandonar os estudos em prol da família, ou no caso daquele aluno que parou de estudar por lhe faltar força emocional e ter se envolvido com drogas, etc.

Importa reconhecer que a escola é responsável por constituir redes de apoio e promover a construção de fatores protetivos aos estudantes e demais membros dessa ecologia de desenvolvimento: familiares, amigos, corpo profissional da escola, comunidade adjacente. Os dados corroboram a importância da escola como microssistema promotor de desenvolvimento e a EJA em sua função protetiva e promotora de resiliência, visto que desenvolve em seus alunos possibilidade de enfrentamento aos riscos, fortalecendo a dignidade humana e formando cidadãos de direitos.

Pedagogos também significaram o acesso dos alunos à EJA como um recomeço, ressaltando o estudo tardio como uma forma de minimizar desigualdades que já se 
constituíram marcas na trajetória dos estudantes. O resgate da autoestima que a EJA favorece, foi elencado tanto pelos alunos quanto pelos pedagogos garantindo a ideia de que a escola proporciona mais do que ensino formal, ela promove desenvolvimento pessoal e formação cidadã.

A dinâmica dos alunos no ambiente escolar também foi um dado significativo. Todos relataram que gostavam muito desse ambiente. Disseram estar mais maduros e puderam aproveitar melhor as interações em sala de aula, nos eventos e palestras que a escola oferecia. O bom contato, a proximidade e atenção entre a equipe pedagógica, professores e alunos oportunizam a permanência desses alunos na escola.

Ao ouvir suas histórias, observou-se quão interessante é o percurso de cada aluno e como, para eles, foi difícil escolher, em determinada época, outra atividade que não estudar. Além disso, a retomada aos estudos é dispendiosa, com idas ao colégio quase todos os dias, voltando para casa tarde da noite ou acordando extremamente cedo para cumprir horário, característica da vida adulta. Cabe às políticas públicas educacionais, à formação de professores para atuação na EJA o esforço de constituir rede de apoio analisando os fatores de risco próprios à população atendida, em seus diferentes grupos, e transformar os fatores de risco identificados em possibilidades de intervenção pedagógica promotora de resiliência nesse contexto.

\section{REFERÊNCIAS}

AMPARO, Deise Matos do; ALCES, Paola Biasoli; CÁRDENAS, Carmen J. Pertencimento e identidade em adolescentes em situação de risco de Brasília. Journal of Human Growth and Development, São Paulo, v. 14, n. 1, p. 11-20, 19 abr. 2004. NEPAS. DOI: http://dx.doi.org/10.7322/jhgd.39787.

ARROYO, Miguel. A educação de jovens e adultos em tempos de exclusão. In: UNESCO. Construção coletiva: contribuições à educação de jovens e adultos. Brasília: UNESCO, MEC, RAAAB, 2005. Disponível em: http://portal.mec.gov.br/index.php?option=com_docman\&view=download\&alias $=655$ vol3const-pdf\&Itemid=30192. Acesso em: 16 jul. 2019.

BARRETO, Vera (coord.). Trabalhando com a Educação de Jovens e Adultos: alunas e alunos da EJA. Brasília: Ministério da Educação, 2006. Disponível em: http://portal.mec.gov.br/secad/arquivos/pdf/eja_caderno1.pdf. Acesso em: 07 dez. 2018. 
BRASIL. [Constituição (1988)]. Constituição da República Federativa do Brasil de 1988. Brasília, DF: Presidência da República, [2016]. Disponível em:

http://www.planalto.gov.br/ccivil_03/Constituicao/Constituiçao.htm. Acesso em: 14 jul. 2019.

BRASIL. Ministério da Educação. Conselho Nacional de Educação. Câmara de Educação Básica. Parecer CNE/CEB no 11, de 10 de maio de 2000. Diretrizes Curriculares Nacionais para a Educação de Jovens e Adultos. Brasília, DF: MEC, 2000. Disponível em: http://portal.mec.gov.br/cne/arquivos/pdf/pceb011_00.pdf. Acesso em: 14 jul. 2019.

BRASIL. Senado Federal. LDB: Lei de Diretrizes e Bases da Educação Nacional. Brasília: 2017. Disponível em:

http://www2.senado.leg.br/bdsf/bitstream/handle/id/529732/lei_de_diretrizes_e_bases_ 1ed.pdf. Acesso em: 25 jun. 18.

BRONFENBRENNER, Urie. A Ecologia do Desenvolvimento Humano:

Experimentos naturais e planejados. Porto Alegre: Artes Médicas, 1996.

BRONFENBRENNER, Urie. Bioecologia do desenvolvimento humano: tornando os seres humanos mais humanos. Tradução de André de Carvalho-Barreto. Porto Alegre: Artmed, 2011.

BRONFENBRENNER, Urie; MORRIS, Pamela A. The Bioecological Model of Human Development. In: LERNER, Richard M. Handbook of child psychology: Theoretical models of human development. 6th ed. Hoboken, NJ: Wiley, 2006. v. 1, p. 793-828. Disponível em: http://edfa2402resources.yolasite.com/resources/Bronfenbrenner Modelof Development.pdf. Acesso em: 01 ago. 2019.

BRUNIERA, David Salvador et al. Pertencimento à Escola: Sentidos atribuídos por alunos do ensino fundamental II. Educação em Análise, Londrina, v. 3, n. 1, p. 133 154, jan./jun. 2018. Disponível em:

http://www.uel.br/revistas/uel/index.php/educanalise/article/view/34375/24845. Acesso em: 15 out. 2019.

CABRAL, Sandra Santos; CYRULNIK, Boris (org.). Resiliência: Como tirar leite de pedra. São Paulo: Casa do Psicólogo, 2015.

CYRULNIK, Boris. Resiliência: Essa inaudita capacidade de construção humana. Lisboa: Instituto Piaget, 2001.

DELL'AGLIO, Débora Dalbosco; KOLLER, Silvia Helena (org.). Adolescência e Juventude: Vulnerabilidade e contextos de proteção. São Paulo: Casa do Psicólogo, 2011. 
DELL'AGLIO, Débora Dalbosco; KOLLER, Silvia Helena; YUNES, Maria Angela Mattar (org.). Resiliência e psicologia positiva: interfaces do risco à proteção. 2. ed. São Paulo: Casa do Psicólogo, 2011.

DESSEN, Maria Auxiliadora; POLONIA, Ana da Costa. A família e a escola como contextos de desenvolvimento humano. Paidéia (Ribeirão Preto), Ribeirão Preto, v. 17, n. 36, p. 21-32, abr. 2007. Disponível em $<$ http://www.scielo.br/scielo.php?script=sci_arttext\&pid=S0103863X2007000100003\&lng=pt\&nrm=iso >. acessos em 17 jul. 2019. https://doi.org/10.1590/S0103-863X2007000100003.

DI PIERRO, Maria Clara. A educação de jovens e adultos no Plano Nacional de Educação: avaliação, desafios e perspectivas. Educação \& Sociedade, Campinas, v. 31, n. 112, p. 939-959, set. 2010. Disponível em:

http://www.scielo.br/scielo.php?script=sci_arttext\&pid=S0101$73302010000300015 \& \operatorname{lng}=e n \& n r m=$ iso. Acesso em: 17 jul. 2019.

HABIGZANG, Luísa Fernanda; DINIZ, Eva; KOLLER, Silvia Helena (org.). Trabalhando com adolescentes: teoria e intervenção. Porto Alegre: Artmed, 2014.

HADDAD, Sérgio. A educação de pessoas jovens e adultas e a nova LDB. São Paulo, 1997. Disponível em: http://hdl.handle.net/11465/1767. Acesso em: 14 jul. 2019.

KOLLER, Silvia Helena; MORAIS, Normanda Araujo de; PALUDO, Simone dos Santos (org.). Inserção Ecológica: Um método de estudos do desenvolvimento humano. São Paulo: Casa do Psicólogo, 2016.

LIBÓRIO, Renata Maria Coimbra; KOLLER, Silvia Helena (org.). Adolescência e Juventude: Risco e proteção na realidade brasileira. São Paulo: Casa do Psicólogo, 2009.

LOPES, Jamille Mansur; OLIVEIRA, Francismara Neves de; CARVALHO, Luciana Ramos Rodrigues de; GODOI, Guilherme Aparecido de. A escolarização dos alunos da EJA e a resiliência: O que revelam as pesquisas das áreas de educação, psicologia e saúde?. Brazilian Journal Of Development, v. 6, n. 7, p. 53066-53082, 2020.

Disponível em: https://www.brazilianjournals.com/index.php/BRJD/article/view/14135. Acesso em: 13 jul. 2021. DOI: http://dx.doi.org/10.34117/bjdv6n7-814.

MELILLO, Aldo; OJEDA, Elbio Néstor Suárez (org.). Resiliência: Descobrindo as próprias fortalezas. Porto Alegre: Artmed, 2005. 
POLETTO, Michele; KOLLER, Sílvia Helena. Contextos ecológicos: promotores de resiliência, fatores de risco e de proteção. Estudos de Psicologia (Campinas),

Campinas, v. 25, n. 3, p. 405-416, set. 2008. Disponível em:

http://www.scielo.br/scielo.php?script=sci_arttext\&pid=S0103-

166X2008000300009\&lng=en\&nrm=iso. Acesso em: 22 out. 2019.

DOI: http://dx.doi.org/10.1590/S0103-166X2008000300009.

SANTOS, Émina. A educação como direito social e a escola como espaço protetivo de direitos: uma análise à luz da legislação educacional brasileira. Educação e Pesquisa, São Paulo, v. 45, e184961, 2019. Disponível em:

http://www.scielo.br/scielo.php?script=sci_arttext\&pid=S1517-

97022019000100508\&lng=pt\&nrm=iso. Acesso em: 14 out. 2019.

DOI: http://dx.doi.org/10.1590/s1678-4634201945184961.

Recebido em: 15/09/2021

Aprovado em: 01/10/2021

Publicado em: 10/10/2021 